\title{
Ex vivo and in silico Molecular Docking Studies of Aldose Reductase Inhibitory Activity of Apigenin from Morus indica L.
}

\author{
Satish Anandan', Murali Mahadevamurthy'2, Chandra3 ${ }^{3}$, Asna Urooj ${ }^{1, *}$ \\ ${ }^{1}$ Department of Studies in Food Science and Nutrition, University of Mysore, Manasagangotri, Mysuru -570 006, Karnataka, INDIA. \\ 2Department of Studies in Botany, University of Mysore, Manasagangotri, Mysuru -570 006, Karnataka, INDIA. \\ ${ }^{3}$ Department of Physics, The National Institute of Engineering (NIE), Mysuru - 570 008, Karnataka, INDIA.
}

\begin{abstract}
Objective: An investigation on Aldose Reductase Enzyme (ALR) inhibitory activity of apigenin (API) isolated from Morus indica L. was evaluated by ex vivo and molecular docking studies. Materials and Methods: The inhibitory efficacy of API from $M$. indica was evaluated against ALR in lens tissue of mice by ex vivo and their binding mechanism through molecular docking was carried out by AutoDock. Results: The API (10-50 $\left.\mu \mathrm{g} \mathrm{mL}^{-1}\right)$ concentration exhibited significant inhibition ( $p \leq 0.05$ ) of ALR enzyme in a dose dependent manner with $I_{50}$ value of $39.23 \mu \mathrm{g} \mathrm{mL}^{-1}$. The positive control aminoguanidine (AG) at $10 \mathrm{mM}$ inhibited $42.96 \%$ of ALR. The molecular docking studies revealed that API showed better binding energy $\left(-9.15 \mathrm{~kJ} \mathrm{~mol}^{-1}\right)$ when compared to AG $\left(-3.78 \mathrm{~kJ} \mathrm{~mol}^{-}\right.$ $\left.{ }^{1}\right)$. Molecular interaction analysis showed that API interrupts the proton donation mechanism which is necessary for the catalytic activity of
\end{abstract}

ALR by forming $\mathrm{H}$-bond with Trp20 (proton donor). Conclusion: The ALR inhibition potential offered by API was further confirmed through molecular docking studies. The present findings support the pharmacological application of API for the treatment of diabetes cataract.

Key words: Mulberry, Antiglycation, Retinopathy, Eye lens.

Correspondence

Dr. Asna Urooj, Professor, Department of Studies in Food Science and Nutrition, University of Mysore, Manasagangotri, Mysuru-570006, Karnataka, INDIA.

Phone: +918212419632

Email: asnaurooj@foodsci.uni-mysore.ac.in

DOI: 10.5530/jyp.2019.11.21

\section{INTRODUCTION}

The accumulation of polyols within human eye lens is a primary contributing factor in cataract formation. Some tissues of the body, including the eye lens, do not require the action of insulin for glucose or other simple sugars like galactose to enter into cells. ${ }^{1}$ In diabetes, the concentration of the sugar is high in the aqueous humour and can diffuse passively into the lens. ${ }^{2}$ The enzyme aldose reductase in the eye lens converts glucose and galactose into sorbitol and galactitol respectively. These polyols cannot readily diffuse out of the lens, which results in the accumulation of oxidative stress thereby leading to hemolysis. ${ }^{3}$

In recent years, the identification of novel molecules by modern computational approaches, based on the three-dimensional structure of the therapeutic target, has increased. Particularly, molecular docking simulations, employed in the computer-aided drug discovery, aid in the prediction of small, promising molecules based on the binding structure of the ligand to its receptor. ${ }^{4}$ The evaluation of ligand orientation and the stability of the receptor-ligand complex is an essential factor in modern computer-aided drug designing process that can be useful for developing potential drug candidates and also for understanding the binding nature. ${ }^{5}$ A number of compounds, both natural and synthetic, have been found to inhibit aldose reductase. Currently, only the carboxylic acid epalrestat, an Aldose Reductase Inhibitor (ARI), is available on the market and is used for the treatment of diabetic neuropathy in Japan, India and China. ${ }^{6}$ Due to the undesirable side effects of available drugs from natural sources which act against diabetic cataract are being investigated which is still essential. $^{7-8}$

In our laboratory, various medicinal plants such as Moringa oleifera, Ficus benghalensis and Morus indica (MI) varieties have been screened for their proximate composition, phytochemical profile, ${ }^{9}$ antioxidant, ${ }^{10}$ anti-hypercholesterolemic, ${ }^{11}$ antimutagenic, ${ }^{12}$ anti-diabetic ${ }^{13}$ and protease activities in both in vitro and ex vivo models. ${ }^{14}$ Further, pre-clinical and clinical studies were carried out for their possible mechanisms of antidiabetic action of Ficus racemosa bark and Morus indica leaves. ${ }^{15}$ In our previous studies, extract of $M$. indica G4 variety has shown a potential anti-glycation effect in BSA-glucose model. ${ }^{16}$ Further, the bioactive compounds of $M$. indica G4 variety were sequentially extracted, identified and quantified by UP-LCMS. Among them, apigenin (API) had the maximum yield and it was isolated by preparative HPLC and characterized by FTIR, NMR and SEM. Apigenin rich extract from $M$. indica has shown a potential anti-glycation effect in all the different stages of protein glycation (unpublished data). To the best of our knowledge and from the results of our previous studies and also, there are no reports on the inhibitory effects of API from M. indica G4 on ALR. Hence, the present study was aimed in evaluating the inhibitory efficacy of API from $M$. indica against ALR in lens tissue of mice ex vivo and to investigate the molecular docking of the binding mechanism of the API to ALR by in silico model.

\section{MATERIALS AND METHODS}

\section{Plant materials}

The leaves of commercial varieties of Morus indica G4 (ISGR Reg. No.: 050564), were collected in the month of May-2016 from Central Sericulture Research and Training Institute (CSRTI), Mysore. Apigenin was isolated from methanol extract of leaves by preparative HPLC and characterized through NMR and UP-LCMS (unpublished data). 


\section{Chemicals}

DL-glyceraldehyde, NADPH, aminoguanidine was purchased from Sigma-Aldrich Chemicals Co. (India). All other chemicals and solvents used were of analytical grade.

\section{Animals}

Healthy adult Swiss Albino mice (25-50 g) aged between 2 to 3 months, were taken for the study. They were housed under standard environmental conditions [ $12 \mathrm{~h}$ light and $12 \mathrm{~h}$ dark cycle, $25 \pm 30{ }^{\circ} \mathrm{C}, 35-60 \%$ relative humidity] in polypropylene cages and maintained on commercial rat chow ad-libitum. All animals had free access to water. The experimental protocol was approved by the Institutional Animal Ethics Committee of University of Mysore, Manasagangotri, Mysuru. (Animal Sanction Order No: UOM/IAEC/06/2017).

Crude ALR was prepared as follows: Lenses were removed from Swiss albino mice (Body weighing 25-50 g) and frozen at $-70{ }^{\circ} \mathrm{C}$ until use. Non-cataractous clear lenses were pooled and a homogenate was prepared in $0.1 \mathrm{M}$ phosphate buffered saline ( $\mathrm{pH}$ 6.2). The ALR homogenate was then centrifuged at $10,000 \mathrm{~g}$ for $20 \mathrm{~min}$ at $4^{\circ} \mathrm{C}$ in a refrigerated centrifuge. The supernatant was collected and used as ALR. ${ }^{17}$

\section{Inhibition of aldose reductase enzyme by apigenin}

The inhibitory activity of the API on ALR was carried out using all the optimized data, in a $1 \mathrm{~mL}$ cuvette with optimize amount of enzyme (750 $\mu \mathrm{g} \mathrm{mL}^{-1}$ protein), varying concentration of API $\left(10-50 \mu \mathrm{g} \mathrm{mL}^{-1}\right)$ in $50 \mathrm{mM}$ sodium-potassium phosphate buffer ( $\mathrm{pH} 6.0$ ) containing $5 \mathrm{mM}$ $\beta$-mercaptoethanol, 0.7 M NADPH, $0.4 \mathrm{M} \mathrm{Li}_{2} \mathrm{SO}_{4}$ and $2.5 \mathrm{mM}$ of glyceraldehyde (substrate) were taken. The reaction was initiated by addition of glyceraldehyde and the change in the absorbance at $340 \mathrm{~nm}$ due to NADPH oxidation was measured spectrophotometrically. ${ }^{18}$

\section{Molecular docking of aldose reductase enzyme with API and AG}

Molecular Docking estimated the characterization of the binding site between the ALR enzyme with API and AG. Docking calculation was performed using AutoDock 4.2 tool with a semi-empirical free-energy force. ${ }^{19}$ The crystal structure of ALR was obtained from Protein Data Bank (PDB ID: 3RX3). The PEG molecule together with water molecules present in the structure was removed and then polar hydrogen atoms and Kollman united atom charges were added. An initial grid volume (126 x 126 x 126 with $1 \AA$ grid spacing $0.375 \AA$ ) covering all surface of the protein was used to improve the free movement of all structures around the protein for evaluation of binding regions. Then a smaller grid volume ( $60 \times 60 \times 60)$ was used to estimate the residues binding and the API and AG and ALR structures, were treated as rigid docking. Default AutoDock parameters with Lamarckian Genetic Algorithm were used. Finally, the best scoring (i.e., with the lowest docking energy or more populated) docked model was chosen to represent the most probable binding mode predicted.

\section{Statistical analysis}

Data from three replicates of each experiment were subjected to analysis of variance (ANOVA) using SPSS Inc. 16.0. Significant effects of treatments were determined by F values $(p \leq 0.05)$. Treatment means were separated by Tukey's HSD test.

\section{RESULTS}

\section{Inhibition of aldose reductase enzyme by apigenin}

The isolated API was evaluated for its potential to inhibit ALR enzyme ex vivo. All the API concentrations $\left(10-50 \mu \mathrm{g} \mathrm{mL}^{-1}\right)$ exhibited significant inhibition $(p \leq 0.05)$ of ALR in a dose-dependent manner from $10 \%$ to $62 \%$, respectively (Figure 1). The $\mathrm{IC}_{50}$ value was found to be $39.23 \mu \mathrm{g} \mathrm{mL}^{-1}$. The positive control (AG) offered $50 \%$ inhibition to ALR at $5.15 \mathrm{mM}$ concentration.

\section{Molecular docking of aldose reductase enzyme with API and $A G$}

Docking results with the free binding energy, ligand efficiency inhibition constant, Van der wall energy + hydrogen bond + desolving energy, number of hydrogen bond, bonding residues and bond length values are listed in Table 1. Docking results API showed binding energy $(-9.15 \mathrm{~kJ}$ $\left.\mathrm{mol}^{-1}\right)$ when compared with the standard AG $\left(-3.78 \mathrm{~kJ} \mathrm{~mol}^{-1}\right)$. The Trp20 and Asp101 amino acid residues interacting with the API and AG with the formation of hydrogen bonds (green dotted lines) is depicted in Figure 2 .

\section{DISCUSSION}

Many structurally diverse phytochemical components have been reported as potent ALR inhibition (ALRI) in vitro. ${ }^{7}$ In the present study, the ALRI by API of $M$. indica could is by preventing either the enzymatic conversion of glyceraldehyde to glycerol and glucose to sorbitol, thereby replenishing

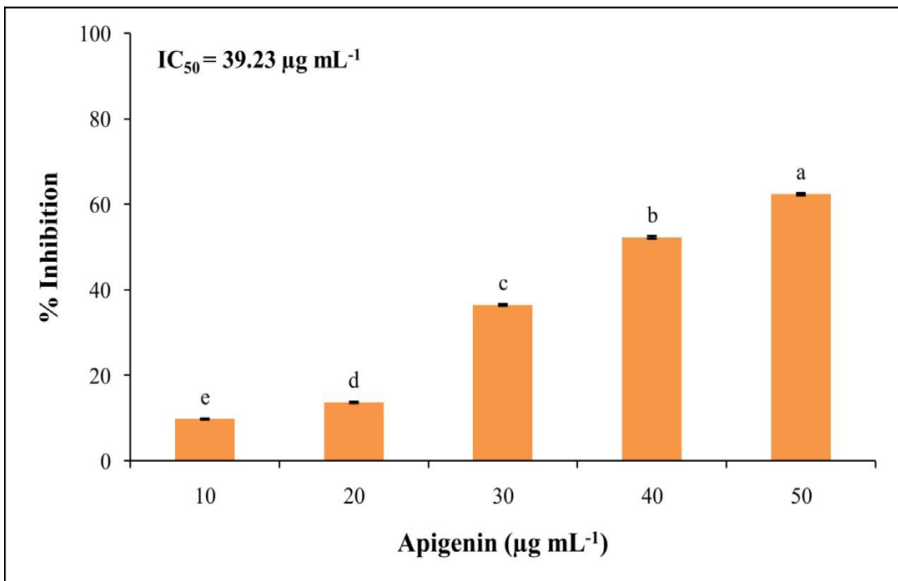

Figure 1: Inhibition of aldose reductase enzyme by apigenin from Morus indica-G4

Table 1: Docking results of apigenin and aminoguanidine with aldose reductase enzyme

\begin{tabular}{ccccccc}
\hline Compounds & $\begin{array}{c}\text { Binding } \\
\text { Energy } \\
(\mathbf{k J} \text { mol-1) }\end{array}$ & $\begin{array}{c}\text { Ligand } \\
\text { Efficiency }\end{array}$ & $\begin{array}{c}\text { Inhibition } \\
\text { Constant }\end{array}$ & $\begin{array}{c}\text { Van der Waals }+ \\
\text { H-bond + Desolve } \\
\text { energy }\end{array}$ & $\begin{array}{c}\text { No. of } \\
\text { H- bonds }\end{array}$ & $\begin{array}{c}\text { Bonding residues } \\
\text { Bond Length } \\
(\AA)\end{array}$ \\
\hline API & -9.15 & -0.46 & 196.65 & -10.13 & 1 & 3RX3:A: TRP20:HN \\
AG & -3.78 & -0.76 & 1.7 & -2.22 & 1 & $\begin{array}{l}\text { 3RX3:A: ASP102:OD2 } \\
\text { 4RX2:A: ASP102:OD2 }\end{array}$ 2.212 \\
\hline
\end{tabular}




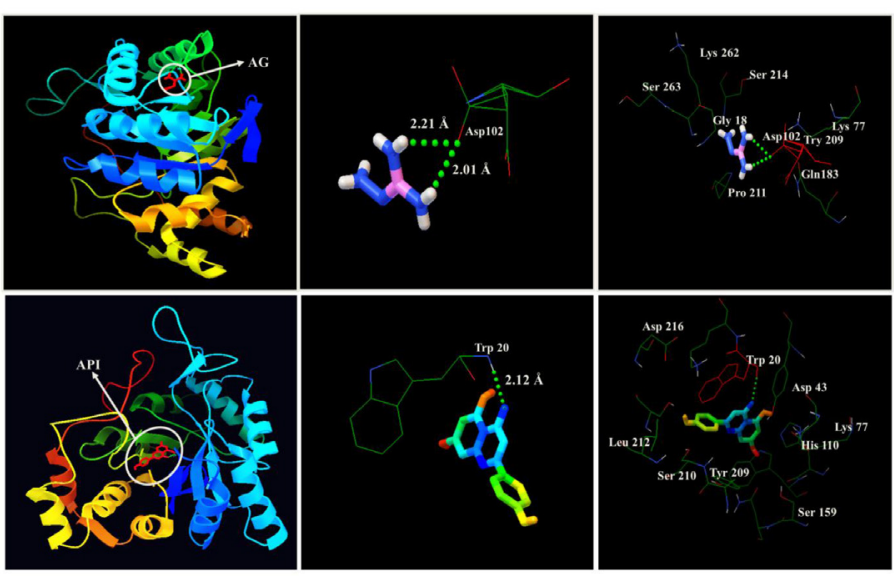

Figure 2: Docked pose of aldose reductase enzyme (3RX3) with apigenin and aminoguanidine. AG: Aminoguanidine; API: Apigenin

the depletion of NADPH levels. As API showed good inhibitory activity against ALR, it can be used to treat diabetic complication in the early stage. Although several synthetic ALR inhibitors such as tolrestat and sorbinil exhibit potent effects, either their use is limited, or they have been withdrawn from clinical trials because of relatively low efficacy, poor permeation and safety issues. ${ }^{8}$ Currently known ALR inhibitors can be classified into the four main groups based on their structures like acetic acid derivatives (tolrestat and epalrestat), cyclic imides (sorbinil), phenolic derivatives (quercetin) and phenylsulfonyl nitro methane derivatives. $^{20}$

Plant-derived compounds having significant ALR inhibitory activity can be classified into specific chemical groups such as flavonoids, tannins, phenolics, alkaloids, terpenoids, coumarins and miscellaneous compounds. The structural requirements of flavonoids for ALR inhibitory are flavones and flavonols having 7-hydroxy and catechol moiety (3' and 4' dihydroxy group) at the $\mathrm{B}$ ring exhibit strong activity and 2-3 double bond enhances activity. Flavones and flavonols have the catechol moiety at the $\mathrm{B}$ ring exhibit stronger activity than those having the pyrogallol (3', ',5'-trihydroxy) moiety. ${ }^{21}$ Structure requirement for phenolics with a hydroxyl group at the $4^{\text {th }}$ position was crucial for ALR inhibitory property and also the presence of the neighbouring-methyl group in phenolics, denature the ALR and inhibits its activity. ${ }^{18}$ ALR inhibitors including quercetin are currently the most commonly used oral agents for their good penetrations through cellular membranes and rapid metabolism of sorbitol by sorbitol dehydrogenase considered for treatment of diabetic complications. $^{22}$

Molecular docking is a frequently used tool in computer-aided structurebased rational drug design. In the present study, we have demonstrated that how API molecules called ligands and the target ALR (macromolecule) fit together by generating binding energies with 3D-structure by using Auto Dock Tools (ADT). In the docking studies, if a compound shows lesser binding energy compared to the standard it proves that the compound has higher activity. ${ }^{23}$ The API showed lesser binding energy when compared to that of standard AG and also potential binding sites of API were very effective when compared with standard AG. By the above study, the binding sites and docking parameters of API possess potential ALR inhibition when compared to AG. This may be attributed due to the differences in the position of the functional groups in that compound. Further research in the development of API and their derivatives as a potential drug candidate for the ALR inhibition must be undertaken.

\section{CONCLUSION}

Apigenin (4', 5,7-trihydroxyflavone) is a natural product belonging to the flavone class that is aglycone and are attractive as a therapeutic agent in the treatment of diabetic complications since there is no toxicity. In this context, we have been investigating aldose reductase inhibitors to prevent diabetic cataract in animals. Thus, we have successfully isolated and purified the aldose reductase inhibitor from Morus indica as apigenin, which has demonstrated its inhibitory efficacy in lens tissues of mice, in both ex vivo and in silico model. Further studies to confirm the retinopathy effect using an animal model are underway.

\section{ACKNOWLEDGEMENT}

This work was performed with financial support from the Indian Council of Medical Research, New Delhi and DRS-UGC-SAP-II, New Delhi. The first author is grateful to Indian Council of Medical Research, New Delhi, for the award of a Senior Research Fellowship. The First author is also thankful to colleagues for assisting in animal experiments. $\mathrm{Mu}-$ rali M., would like to acknowledge the University Grants Commission (UGC)- New Delhi, India for providing the financial support under UGC Post-Doctoral Fellowship for SC/ST Candidates (No. F/PDFSS2015-17-KAR-11846). We are also grateful to Institution of Excellence (IOE) and University with Potential for Excellence (UPE), University of Mysore, Mysuru for providing instrumentation facilities.

\section{CONFLICT OF INTEREST}

The authors declare no conflict of interest.

\section{ABBREVIATIONS}

ALR: Aldose reductase enzyme; API: Apigenin; AG: Aminoguanidine.

\section{REFERENCES}

1. Gupta SK, Selvan VK, Agrawal SS, Saxena R. Advances in pharmacological strategies for the prevention of cataract development. Indian J Ophthalmol. 2009;57(3):175.

2. Davies PD, Duncan G, Pynsent PB, Arber DL, Lucas VA. Aqueous humour glucose concentration in cataract patients and its effect on the lens. Exp Eye Res. 1984;39(5):605-9.

3. Chung SS, Ho EC, Lam KS, Chung SK. Contribution of polyol pathway to diabetes-induced oxidative stress. J Am Soc Nephrol. 2003;14(suppl 3):S233-6.

4. Madeswaran A, Umamaheswari M, Asokkumar K, Sivashanmugam T, Subhadradevi $\bigvee$, Jagannath P. Discovery of potential aldose reductase inhibitors using in silico docking studies. Orient Pharm Exp Med. 2012;12(2):157-61.

5. Maithri G, Manasa B, Vani SS, Narendra A, Harshita T. Computational drug design and molecular dynamic studies- A review. Int J Biomed Data Min. 2016;6(01):1-7.

6. Reddy TN, Ravinder M, Bagul P, Ravikanti K, Bagul C, Nanubolu JB, et al. Synthesis and biological evaluation of new epalrestat analogues as aldose reductase inhibitors (ARIs). Eur J Med Chem. 2014;71:53-66.

7. Kawanishi $\mathrm{K}$, Ueda $\mathrm{H}$, Moriyasu M. Aldose reductase inhibitors from the nature. Cur Med Chem. 2003;10(15):1353-74.

8. Manzanaro S, Salvá J, de la Fuente JÁ. Phenolic marine natural products as aldose reductase inhibitors. J Nat Prod. 2006;69(10):1485-7.

9. Reddy VP, Urooj A. Proximate, phytochemical profile and antioxidant activity (in vitro and ex vivo) of Morus indica varieties. Int J Pharm Sci Res. 2013;4(4):1626.

10. Satish A, Reddy PV, Sairam S, Ahmed F, Urooj A. Antioxidative Effect and DNA protecting property of Moringa oleifera root extracts. J Herbs Spices Med Plants. 2014;20(3):209-20.

11. Reddy V, Urooj A, Sairam S, Ahmed F. Hypocholesterolemic Effect of Moringa oleifera Polyphenols in Rats Fed High Fat-Cholesterol Diet. Mal J Nutr. 2017;23(2):473-8.

12. Satish A, Kumar RP, Rakshith D, Satish S, Ahmed F. Antimutagenic and antioxidant activity of Ficus benghalensis stem bark and Moringa oleifera root extract. Int J Chem Anal Sci. 2013;4(2):45-8.

13. Ahmed F, Chavan S, Satish A, Punith KR. Inhibitory activities of Ficus benghalensis bark against carbohydrate hydrolyzing enzymes-An in vitro study. Pharmacogn J. 2011;3(20):33-7. 
14. Satish A, Sairam S, Ahmed F, Urooj A. Moringa oleifera Lam.: Protease activity against blood coagulation cascade. Pharmacogn Res. 2012;4(1):44.

15. Urooj A, Ahmed F. Ficus racemosa and Morus indica: Emerging alternative antihyperglycemic agents. In Open Conf Proc J. 2013;4:59-65.

16. Anandan S, Kotebagilu NP, Shivanna LM, Urooj A. Inhibitory potency of C-glycosyl flavonoids from morus $\mathrm{sp}$. on advanced glycation end products. J Biol Act Prod Nat. 2017;7(5):391-400.

17. Halder N, Joshi S, Gupta SK. Lens aldose reductase inhibiting potential of some indigenous plants. J Ethnopharmacol. 2003;86(1):113-6.

18. Chethan S, Dharmesh SM, Malleshi NG. Inhibition of aldose reductase from cataracted eye lenses by finger millet (Eleusinecoracana) polyphenols. Bioorg Med Chem. 2008;16(23):10085-90.

19. Morris GM, Huey R, Lindstrom W, Sanner MF, Belew RK, Goodsell DS, Olson AJ
AutoDock4 and AutoDockTools4: Automated docking with selective receptor flexibility. J Comput Chem. 2009;30(16):2785-91.

20. Veeresham C, Rama RA, Asres K. Aldose reductase inhibitors of plant origin. Phytother Res. 2014;28(3):317-33.

21. Matsuda H, Morikawa T, Toguchida I, Yoshikawa M. Structural requirements of flavonoids and related compounds for aldose reductase inhibitory activity. Chem Pharm Bull. 2002;50(6):788-95

22. Patel DK, Kumar R, Kumar M, Sairam K, Hemalatha S. Evaluation of in vitro aldose reductase inhibitory potential of different fraction of Hybanthusenneaspermus Linn F. Muell. Asian Pac J Trop Biomed. 2012;2(2):134-9.

23. Cosconati S, Forli S, Perryman AL, Harris R, Goodsell DS, Olson AJ. Virtual screening with AutoDock: theory and practice. Expert Opin Drug Discov. 2010;5(6):597-607.

Article History: Submission Date : 28-07-2018 ; Revised Date : 30-09-2018; Acceptance Date : 25-10-2018.

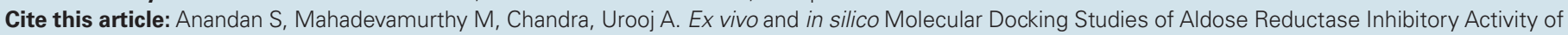
Apigenin from Morus indica L. J Young Pharm. 2019;11(1):101-4. 